\title{
EDITORIAL
}

\section{Missed nursing care - what went wrong?}

\section{Dear Readers,}

Missed nursing care can be categorized as an error of omission. It means that some nursing care is delayed, only partially completed, or not completed at all.

Kalisch et al. (2006) have developed a conceptual model of missed nursing care. According to this model, the structural factors contributing to missed nursing care include: labor resources, material resources, and teamwork and communication. If any of these resources is lacking, nurses are obliged to prioritize their tasks, and at this point nursing care might be delayed or omitted. The problem of missed care is a well-established concept in the nursing literature. Evidence of missed care exists - the problem has been studied in a number of countries (Kalisch, 2006; Ausserhofer et al., 2014; Ball et al., 2016). Recently, Jones et al. (2015) published an integrated review on the subject of missed care, and found that three conceptualizations of omitted care have been developed by different research teams: care left undone (Sochalski et al., 2009); implicit rationing of care (Schubert et al., 2008); and missed care (Kalisch, 2006; Kalisch, Landstrom, Hinshaw, 2009). All proposed conceptualizations look to examine the relationships between organizational factors such as staffing levels, and client and staffing outcomes. These concepts highlight the problem inherent in identifying which nursing tasks and activities are omitted when there is a lack of time and resources, making the provision of necessary care difficult (Ausserhofer et al., 2014; Jones et al., 2015). Currently, we have tools with which we can measure missed nursing care, but ongoing research is required on the use of such tools. Missed care can be measured by the "Tasks left undone" scale developed by Lucero et al. (2009). This 12-item scale asks nurses to identify patient care activities on their last shift that they considered necessary, but which were left undone. Another measure is the BERNCA questionnaire developed by Schubert et al. (2008) which allows measurement of the levels of implicit rationing of nursing care in acute care hospitals. Kalisch and Williams (2009) proposed a MISSCARE survey to measure missed nursing care, and to identify the reasons for missed nursing care.

It is necessary to understand that the most important predictors of missed nursing care are staffing levels and teamwork. Nowadays, as we face a global lack of nurses, missed care is a common threat, and should, therefore, garner greater recognition, since it can manifest itself as a potentially dangerous medical error. Therefore, the problem of missed nursing care deserves special attention. Further studies using the validated tools are advisable.

\section{Prof. Izabella Uchmanowicz, PhD, RN, FESC Member of International Editorial Board Department of Clinical Nursing, Faculty of Health Sciences Wroclaw Medical University, Poland}

\section{References}

Ausserhofer D, Zander B, Busse R, Schubert M, De Geest S, Rafferty AM, Ball J, Scott A, Kinnunen J, Heinen M, Sjetne IS, MorenoCasbas T, Kózka M, Lindqvist R, Diomidous M, Bruyneel L, Sermeus W, Aiken LH, Schwendimann R, RN4CAST consortium. Prevalence, patterns and predictors of nursing care left undone in European hospitals: results from the multicountry cross-sectional RN4CAST study. BMJ Quality \& Safety. 2014;23(2):126-135.

Ball JE, Griffiths P, Rafferty AM, Lindqvist R, Murrells T, Tishelman C. A cross-sectional study of "care left undone" on nursing shifts in hospitals. Journal of Advanced Nursing. 2016;72(9):2086-2097.

Jones TL, Hamilton P, Murry N. Unfinished nursing care, missed care, and implicitly rationed care: state of the science review. International Journal of Nursing Studies. 2015;52(6):1121-1137.

Kalisch BJ. Missed nursing care: a qualitative study. Journal of Nursing Care Quality. 2006;21(4):306-313.

Kalisch BJ, Landstrom GL, Hinshaw AS. Missed nursing care: a concept analysis. Journal of Advanced Nursing. 2009;65(7):1509-1517.

Kalisch BJ, Williams RA. Development and psychometric testing of a tool to measure missed nursing care. Journal of Nursing Administration. 2009;39(5):211-219.

Lucero RJ, Lake ET, Aiken LH. Variations in nursing care quality across hospitals. Journal of Advanced Nursing. 2009;65(11):2299-2310. Schubert M, Glass TR, Clarke SP, Aiken LH, Schaffert-Witvliet B, Sloane DM, De Geest S. Rationing of nursing care and its relationship to patient outcomes: the Swiss extension of the International Hospital Outcomes Study. International Journal for Quality in Health Care. 2008;20(4):227-237.

Sochalski J, Estabrooks CA, Humphrey CK. Nurse staffing and patient outcomes: evolution of an international study. Canadian Journal of Nursing Research. 2015;41(3):320-339. 